\title{
Change of pore-water pressure on creep behavior of an unsaturated silty soil
}

\author{
Tomoyoshi Nishimura ${ }^{\text {i) }}$ and Nanako Tamuraii)
}

\begin{abstract}
i) Professor, Department of Civil Engineering, Ashikaga University, 268, Omae, Ashikaga, Tochigi 326-8558, Japan.
ii) Undergraduate Student, Department of Civil Engineering, Ashikaga University, 268, Omae, Ashikaga, Tochigi 326-8558, Japan.
\end{abstract}

\begin{abstract}
Slope failure induced by rainfall is related to change of effective stress, and both saturated soils and unsaturated soils had been evaluated in effective stress theory. The effective stress comprised confining pressure and pore-water pressure, and unsaturated soil necessary to two stress variables such as net normal stress and matric suction. Before occurrence of slope failure, soils stated under stress condition, which was not isotopic compression stress. Therefore, it was estimated that lateral stress was lower than overburden pressure or dead loading pressure in practice. Mechanical deformations as consolidation or creep behavior was revealed, and associated to slope failure, differential settlement and lateral flow. At least, these problems have been recognized of geotechnical disasters.
\end{abstract}

Keywords: creep behavior, unsaturated soil, suction, pressure membrane technique

\section{INTRODUCTION}

Slope failure induced by rainfall is related to change of effective stress, and both saturated soils and unsaturated soils had been evaluated in effective stress theory. The effective stress comprised confining pressure and pore-water pressure, and unsaturated soil necessary to two stress variables such as net normal stress and matric suction. Before occurrence of slope failure, soils stated under stress condition, which was not isotopic compression stress. Therefore, it was estimated that lateral stress was lower than overburden pressure or dead loading pressure in practice. Mechanical deformations as consolidation or creep behavior was revealed, and associated to slope failure, differential settlement and lateral flow. At least, these problems have been recognized of geotechnical disasters.

Creep deformations induced at slope and embankment as above mentioned was one of important problems in geotechnical and geo-environmental mechanics. Firstly, creep deformations for saturated soft soil have been investigated by some researcher, for instance, Bishop (1969), Bishop and Lovenbury (1969), Vyalov (1969). Feda (1992), Kierzkowski (2007), Brandes and Nakayama (2010), Enomoto et al. (2016), Liu et al. (2016) described creep characteristic using various difference soil materials and established accurate simulation concepts. Unsaturated soils widely existence in both artificial construction structures and ground surface. It was accepted that unsaturated soil properties such as hydro-conductivity, water retention activity, strength, compressibility, volume change and resistance to cyclic loading were affected on suction and suction was defined difference between pore-air pressure and pore-water pressure. Particularly, changing of shear strength in unsaturated soils obviously depend on suction value. While suction was similar to air-entry value, effort of suction to shear resistance e was sufficiently large, the increment of shear strength according to suction often coincident with angle of internal friction of saturated soils. When suction decreased till zero suction value as the converse phenomena associated to hydro-mechanics, further reduction in shear strength was observed with producing hysteresis in soil moisture retention properties. Thus, experimental works and interpretations for suction efforts were reported in below literatures; Blatz et al. (2002), Mendoza and Colmenares (2006), Bilotta, et al. (2008), Ye et al. (2014). On an interdisciplinary study in unsaturated soil practice problems, some exemplifications as above mentioned was impossible to cope evaluate unsaturated soil creep behavior with considerable suction efforts, time dependent behavior or stress-strain characteristic associated to time dependent were discussed with exclude of suction at soil particle together (Kavazanjian and Mitchell (1980), Graham et al. (1983), Mesri and Choi (1985), Lin HD and Wang (1998), De Gennaro et al. (2003), Deng and Tatsuoka (2007), Oldecop and Alonso (2007)). Then suggestion of establish mathematical simulation models (for instance, Liingaard et al. (2004), Gennaro and Pereira (2013)) was provided without the influence of suction on intrinsic properties. To attempt or reconsider investigation of creep behavior of unsaturated soils was significant important perspective under this multidisciplinary circumstance. As a limited experimental paper involving suction controlling test, test results obtained by Lai et al. 
(2014) were described satisfactory data sets and was expected more expansion to unsaturated soil creep characteristic in detail.

This study conducted out unsaturated soil creep test using modified unsaturated soil triaxial apparatus, which was applicable to control two pore-pressure such as pore-water and pore-air pressures under elaborate design. Matric suction was controlled and measured during processing of creep behavior of vertical strain. measurement. Confine pressure of $100 \mathrm{kPa}$ was applied to specimen in the chamber, and specimen was operated in seepage to apparent saturation. For specimen having matric suction of $20 \mathrm{kPa}$ creep stresses were applied step by step up to failure deformation under untrained conditions.

\section{SOIL MATERIAL}

This test program used DL-clay, which fall as silt, and a relatively uniform grain size distribution. Fine component occupy $99.0 \%$ Soil-water characteristic curve was evidenced as shown in Fig. 1 which was measured using pressure membrane method. Suction ranges was less than $20 \mathrm{kPa}$ in SWCC test. SWCC consist of two process (i.e. drying process and wetting process) that degree of saturation obviously indicated between difference between drying and wetting process and it was existence of hysteresis in hydro-mechanical properties. Measurement of pore-water pressure of compacted unsaturated soil was conducted to ascertain initial suction of compacted soil. Each negative porewater pressure was $-8.2 \mathrm{kPa}$ and $-14.6 \mathrm{kPa}$, respectively as shown in Fig. 2. Small water content was large porewater pressure below zero that it was common in empirically. Relationship between deformation and suction effort in unsaturated soil is readily testable and reduction of initial suction was described as shown in Fig. 3. Omitting the detail cyclic unsaturated soil triaxial test procedure, suction in unsaturated soils subjected a given cyclic stress ratio shrinkage volume deformation, and its deformation leaded to reduction of suction. Thus, the results were should be verified in a generalized experimental case.

\section{TEST PROCEDURE}

This study was conducted out unsaturated soil creep stress-deformation test with measurement of two fluid pressures (i.e. pore-air pressure and pore-water pressure) . On unsaturated creep stress-deformation test, unsaturated triaxial apparatus was used which was in highly organized quality for obtaining experimental works and was overwhelming contribution to aim of this study. The apparatus was constructed for further multiplicity of elements that consist of triaxial cell, supply system for cell pressure, pore-water pressure, pore-air pressure, volume change and axial displacement. The cell pressure, pore-water-pressure and pore-air pressure can be controlled as accurately as possible

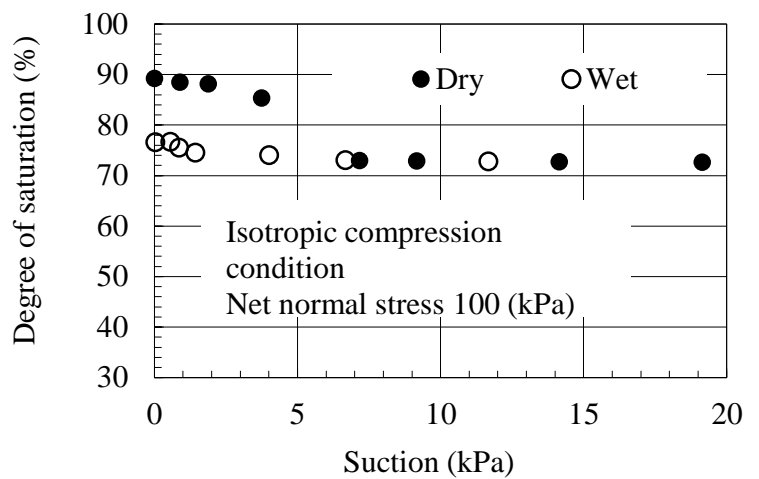

Fig. 1. SWCC using micro porous membrane.

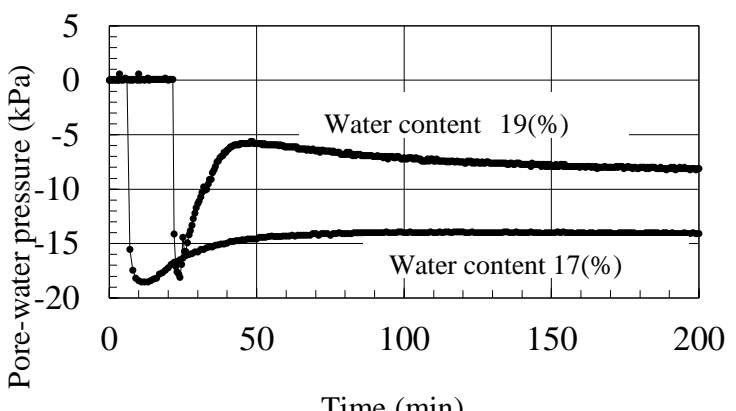

Fig. 2. Measurement of negative pore-water pressure for compacted specimens.

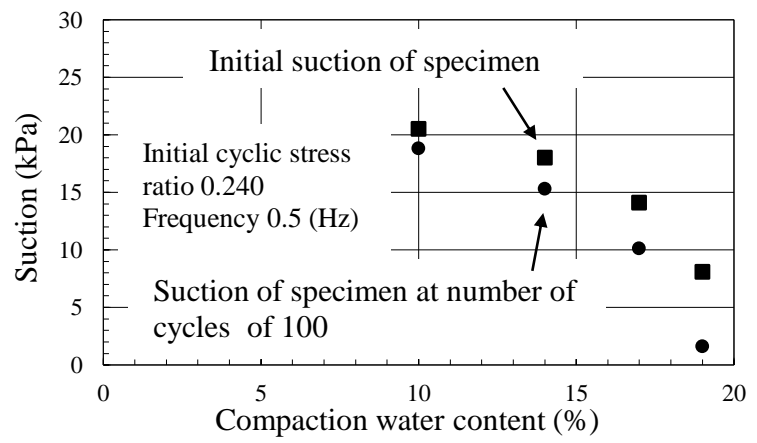

Fig. 3. Reduction of suction due to cyclic loading.

which they were performed using high quality regulators adjusted. Volume change of soil specimen under both isotropic confining pressure and creep stress was measured using gap sensor installed into the inner cell. The gap sensor measured voltage changes which can be translated to volume changes. A solenoid-controlled valve is installed carefully near specimen cap which connected pressure sensor. The axis translation technique was used applying matric suction to soil specimen under constant net normal stress. The micro porous membrane which had an air entry value of 250 $\mathrm{kPa}$ was installed into the modified pedestal. Nishimura et al. (2012) and Wang et al. (2014) developed pressure technique using micro-porous membrane instead of ceramic disc in a general way that there were two important aspects as following; time consuming for testing and an overt characteristic such as extremely low hydraulic conductivity in ceramic disc own. Compacted specimen had a water content of $10.0 \%$, 


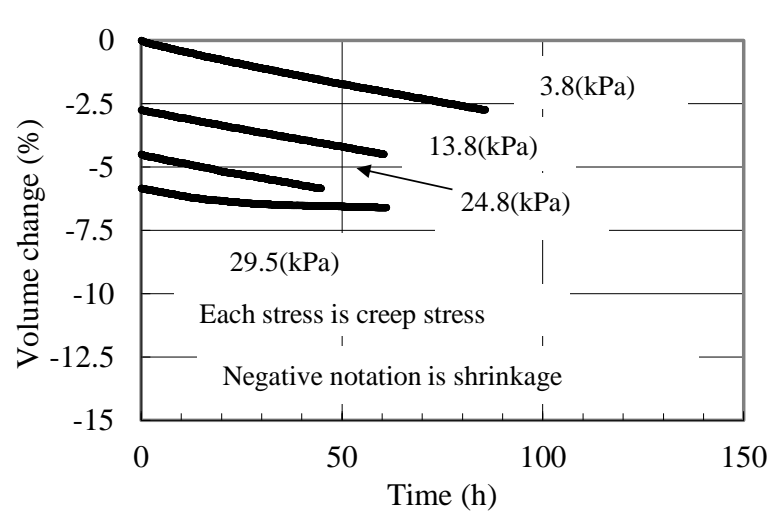

Fig. 4. Shrinkage of specimen subjected to creep stress.

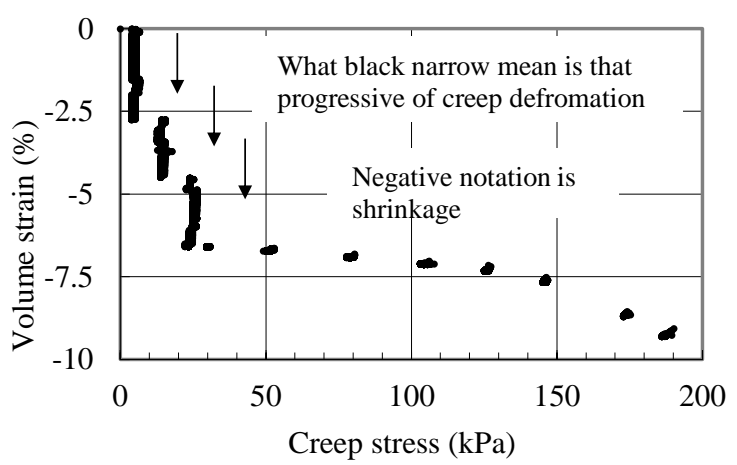

Fig. 5. Relationship between creep stress and volume strain.

a dry density of 1.387 and void ratio of 0.853 that sizes were a height of $10.0 \mathrm{~cm}$ and diameter of $5.0 \mathrm{~cm}$, respectively. Isotropic confining pressure of $100 \mathrm{kPa}$ was applied and after equilibrium of volume of specimen seepage flow was performed to delete initial suction. Subsequently, suction of $20 \mathrm{kPa}$ was applied that was recurrence of unsaturation-saturation-unsaturation to an intrinsic property. Then, creep test commenced with measurement excess pore-water pressure under undrained conditions. Determination of creep stresses and equilibrium period associated to volume deformation were at least randomly or remained unspecified.

\section{CREEP BEHAVIOR WITH SUCTION}

Unsaturated soil creep phenomena were significant problems in geotechnical practice. Creep behavior for saturated-unsaturated soils fact have been more problematized widely. This study focused on creep behavior that varify a more comprehensive characterization for evaluation of safety factors. Measured volume change of specimen with both initial suction of $20 \mathrm{kPa}$ and Isotropic confining pressure of 100 $\mathrm{kPa}$ with time were shown in Fig. 4 with extraction four creep stress cases from all data sets. Shrinkage deformations with time were smoothly accumulated, the time dependent characteristic was sufficiently recognized. Figure 5 indicated relationship between creep stress and volume strain involving time dependent characteristic (i.e. advancement of deformations). Creep

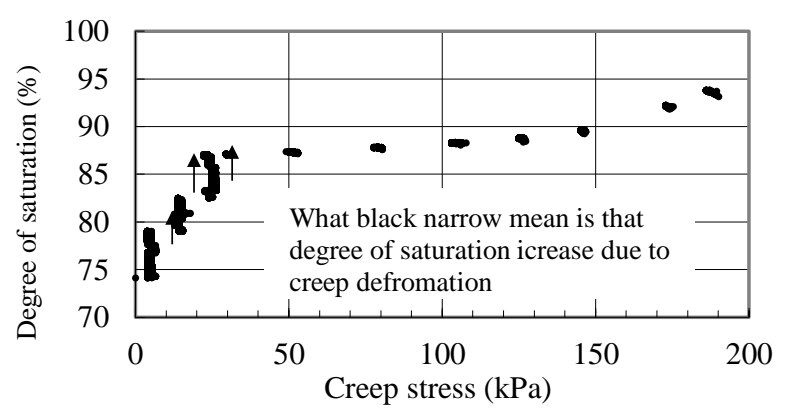

Fig. 6. Increment of degree of saturation according to creep stress.

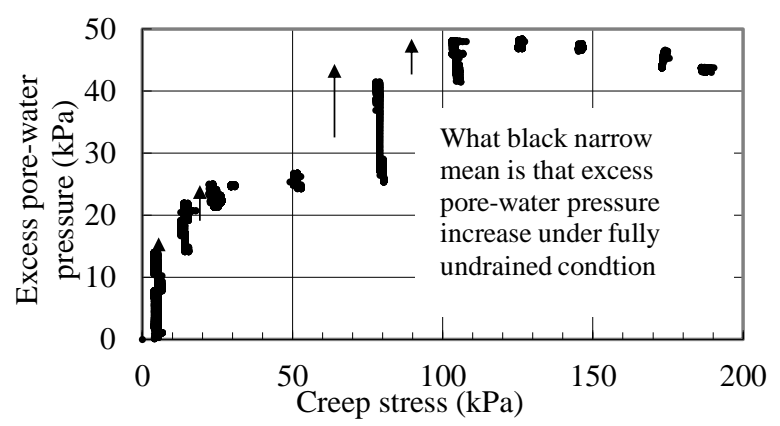

Fig. 7. Significant increment of excess pore-water pressure.

stress was a far-reaching influence on volume shrinkage in this fashion. The tendency seemed to remain that creep stress was $200 \mathrm{kPa}$ neighborhood. Increment of degree of saturation with progressive of shrinkage was shown in Fig. 6. At beginning of creep test, increment was rapidly till creep stress was close $50 \mathrm{kPa}$. Behind it, few produces were measured, and degree of saturation approached to saturation. Specimen was less than $95 \%$ in degree of saturation at end of creep test.

To measure excess pore-water pressure advantages is quite important to associate effective stress changing in mechanical concept. Figure 7 described relationship between creep stress and excess pore-water pressures including all test data sets. The specimen produced further pore-water pressures increment under undrained condition. Occurrence excess pore-water pressure of $48.4 \mathrm{kPa}$ correspond to creep stress of $126.4 \mathrm{kPa}$ was specified as maximum pressures. It verified deletion of suction that excess pore-water pressure was over initial suction in specimen.

This study considered unsaturated soil creep behavior with a variety of factors that monotonic triaxial compression test for saturated soil under undrained condition. Relationship between deviator stress and axial strain was indicated Fig. 8 as general stress- strain curve and undrained triaxial compression test results as above mentioned were combined into Fig. 8. The smoothly curve was results obtained triaxial compression, and patches of black small points were creep behavior. Deviator stresses under applying continuous axial strain immediately remained low values comparison with that of creep stresses all axial strain ranges. Figure 9 showed effective stress paths for both creep behavior and triaxial test results and specified failure line was established on 


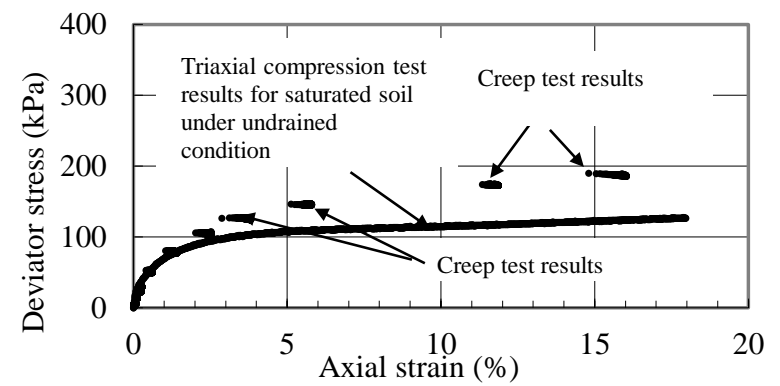

Fig. 8. Stress vs strain properties for creep test and triaxial test.

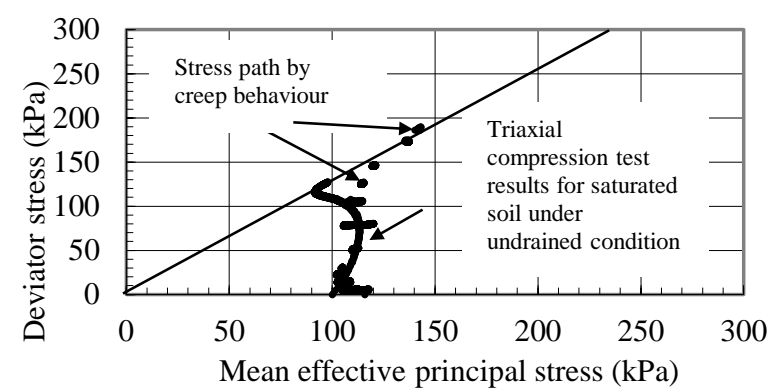

Fig. 9. Effective stress paths.

assumption of effective cohesion of zero. Even mean effective principal stress path was difference, end of effective stress path approach same stress conditions, consequently.

\section{CONCLUSIONS}

Unsaturated soil creep deformations are significant problems associated to time-dependent properties and should be recognized, refereed as hydro0mechanical properties. This study conducted out unsaturated creep test, suction measurement was assembled into test simultaneously in an original fashion. It was accepted that deformation of unsaturated soil was influenced by suction. Such theories and experimental properties were corroborated by the unsaturated soil creep test in more usefully.

\section{REFERENCES}

1) Bilotta, E., Foresta, V. and Migliaro, G. (2008): The influence of suction on stiffness, viscosity and collapse of some volcanic ashy soils. 1st European Conference on Unsaturated Soils, Durham, England, Vol.1, 349-354.

2) Bishop, A.W. (1969): Creep characteristics of two undisturbed clays, Proceedings of the 7th International Conference on Soil, Mechanics, Mexico, Vol.1, 29-37.

3) Bishop, A.W. and Lovenbury, H.T. (1969): Creep characteristics of two undisturbed clays. In Proceedings of the 7th ICSMFE, Mexico. Vol. 1, 29-37.

4) Blatz J.A., Graham, J. and Chandler, N.A. (2002): Influence of suction on the strength and stiffness of compacted sandbentonite, Canadian Geotechnical Journal, 39(5), 10051015.

5) Brandes, H. G. and Nakayama, D. D. (2010): Creep, strength and other characteristics of Hawaiian volcanic soils. Geotechnique, 60(4), 235-245.

6) De Gennaro, V. A, Delage, P. and Cui, Y.J. (2003): Time dependent behavior of oil reservoir chalk: a multiphase approach. Soils and Foundations, 43(4), 131-147.
7) De Gennaro, V. A. and Pereira, J .M. (2013): Viscoplastic constitutive model for unsaturated geomaterials. Computers and Geotechnics, No.54, 143-151. (DOI: 10.1016/j.compgeo.2013.06.005)

8) Deng, J. L. and Tatsuoka, F. (2007): Viscous property of kaolin clay with and without ageing effects by cementmixing in drained triaxial compression. soil stress-strain behavior: measurement, modeling and analysis. In Proceedings of the Geotechnical Symposium, Roma, 399-412.

9) Enomoto, T., Koseki, J., Tatsuoka, F. and Sato, T. (2016): Creep failure of natural gravelly soil and its simulation. Geotechnique, 66(11), 865-877.

(DOI: 10.1680/jgeot.15.p.144)

10) Feda, J. (1992): Creep of soils and related phenomena. Development in geotechnical engineering, Elsevier Science, Vol. 68.

11) Graham, J., Crooks, J.H.A. and Bell, A.L. (1983): Time effects on the stress-strain behaviour of natural soft clays. Geotechnique 33(3), 327-340.

12) Kavazanjian, Jr. E. and Mitchell, J. K. (1980): Timedependent deformation behavior of clays. Journal of Geotechnical Engineering, 106(6), 611-630. (DOI: 10.1016/0148-9062(81)90332-6)

13) Kierzkowski, P. (2007): Oedometer creep tests of a partially saturated kaolinite clay. Proceedings 2nd International Conference on Mechanics of Unsaturated Soils. Vol.112, 301-307.

14) Lai, X. L., Wang, S. M., Ye, W. M. and Cui, Y. J. (2014): Experimental investigation on the creep behavior of an unsaturated clay. Canadian Geotechnical Journal, 51(6), 621-628.

15) Liingaard, M., Augustesen, A. and Lade, P.V. (2004): Characterization of models for time-dependent behavior of soils. International Journal of Geomechanics 4(3), 157-177.

16) Liu, J., Liu, W., Liu, P., Yang, C., Xie, Q. and Liu, Y. (2016): Preliminary research on the theory and application of unsaturated Red-layers embankment settlement based on rheology and consolidation theory. Environmental Earth Sciences, 75(6), 503-523. (DOI: 0.1007/s12665016-5313-2)

17) Lin, H.D. and Wang, C.C. (1998): Stress-strain-time function of clay. Journal of Geotechnical and Geoenvironmental Engineering, 124(4), 289-296.

18) Mendoza, C. and Colmenares, J. (2006): Influence of the suction on the stiffness at very small strains. In Proceedings of Unsaturated Soils 2006. 529-540.

19) Mesri, G. and Choi, Y.K. (1985): Settlement analysis of embankments on soft clays. Journal of Geotechnical Engineering, 111, 441-46.

20) Nishimura, T., Koseki, J., Fredlund, D.G. and Rahardjo, H. (2012): Microporous membrane technology for measurement of soil-water characteristic curve. Geotechnical Testing Journal, Vol. 35, 201-208.

21) Oldecop, L.A. and Alonso, E.E. (2007): Theoretical investigation of the time-dependent behaviour of rockfill. Géotechnique 57(3): 289-301.

22) Vyalov, S. S. (1969): Creep and long-term strength of soils subjected to variable load. Proceedings of the 7th International Conference on Soil Mechanics, Mexico, Vol.1, 423-431.

23) Wang, H., Koseki, J. and Nishimura, T. (2014): SWCC measurement of two types of iron ores. Proc. 6th Int. Conf. on unsaturated soils, Unsat2014, Sydney, 973-979.

24) Ye, W., Lai, X., Wang, Q., Chen, Y., Chen, B. and Cui, Y. (2014): An experimental investigation on the secondary compression of unsaturated GMZ01 bentonite Applied Clay Science, Vol.97-98, 104-109. (DOI: 10.1016/j.clay.2014.05.012) 